\title{
IMPROVING THE ORDER PICKING EFFICIENCY BY OPTIMISING THE ORDERS' SEQUENCE
}

\author{
Zivanic, D. ; Zelic, A.*; Lalic, B. ${ }^{*}$; Simeunovic, N. ${ }^{*} \&$ Szabo, L. ${ }^{* *}$ \\ *Faculty of Technical Sciences, University of Novi Sad, Novi Sad, Serbia \\ ${ }^{* *}$ Faculty of Business Administration, Budapest Business School, Zalaegerszeg, Hungary \\ E-Mail: zivanic@uns.ac.rs, zelic@uns.ac.rs,blalic@uns.ac.rs,nsimeun@uns.ac.rs, \\ szabo.laszlo4@uni-bge.hu
}

\begin{abstract}
One particular activity that substantially affects the efficiency of material flow within supply chains, and which is located within the distribution centre, is order picking. The performance of an order picking system is typically determined by batching, picking sequence, storage policy, zoning, layout design, picking equipment and design of picking information. The main research problem in this paper was to investigate whether the sequence of order execution can have an effect on the performance of the order picking system. The original bound cavities method has been developed, which defines the sequence of execution of received orders in "pick and pass" systems, where the tendency is to perform zone changes in places where there is a continuity of no items for extraction. The paper shows the total picking time and time saving calculations, as well as benefits of its use, which are proven through simulation models of a zone order picking system with two and three pickers.

(Received in October 2018, accepted in January 2019. This paper was with the authors 1 month for 1 revision.)
\end{abstract}

Key Words: Order Picking, Simulation, Logistics, Order Execution, Picking Time

\section{INTRODUCTION}

The most important logistics activity in distribution centres is order picking. Order picking systems represent a functionally complete whole, with elements that allow the execution of specific distribution tasks. Although modern distribution centres are to a great extent automated, in order picking systems, in most cases humans cannot be replaced by machines. Due to the high proportion of time-consuming manual tasks, order picking is looked upon as the most labour cost-intensive distribution activity, [1]. Therefore, there is a need for the organizational and technological solutions in order to improve the efficiency of picking, [2]. The average costs of order picking, in relation to the total costs of a distribution centre, can go up to $50-75 \%$ [1]. The focus of this paper is on zoned ,,pick and pass” order picking systems.

The execution of an order can due to its volume be divided into several zones, where each picker is assigned to one zone. The advantage of order picking zones is the fact that each picker is moving within a relatively small area, thus reducing the possibility of mutual interference, and providing the opportunity for each picker to become familiar with the items in his zone. At this point the process can take place as "pick and pass" and parallel zone picking.

"Pick and pass" zone order picking involves the execution of one or more orders in a sequence, through several zones arranged in an array. Each picker completes a certain part of an order, which includes items belonging to the zone covered by him, and dispatches the tote (by hand or conveyor) with the selected items to the picker covering the next zone, and so on. This order picking method is very effective when individual orders are evenly distributed throughout the zones, i.e. when each zone is providing an equal number of items. It requires the same order picking technology and similar equipment in all of the zones, [3]. It is not suitable in the case of large distances between the zones and a lack of fast transportation means connecting the zones. Another disadvantage is the necessity for having a picker pass 
through all of the zones, even in cases when there are individual zones from which no item has to be taken. During zone order picking, a frequent occurrence is that the totes containing the items become accumulated between the individual zones. On the other hand, it happens that some pickers end up waiting for a tote in order to extract items from the zone that they are covering. In both cases, it can be concluded that the loads on pickers are not well synchronized, i.e. not well balanced. In order to balance the load among pickers when it comes to zone order picking, heuristic algorithms have been developed with the task to adjust the sizes of the zones to the fluctuations in the structure of orders, [4]. The algorithms include an analysis of previous orders, based on the locations of items within the picking zones, in aim to balance the load on the pickers as much as possible. This approach was expected to ensure a balance of the loads over a longer period of time. However, as order structures vary significantly, and are rapidly changing in today's logistics systems, practice has shown that in real order picking systems it is practically impossible to maintain a balance of loads on the pickers over a longer period without changing the locations of the items.

\section{LITERATURE REVIEW}

The most important influences on the performance of a zone order picking system are the shape of the zones, the number of items per order, and the deployment strategy, which has been proven through the use of the simulation models [5]. Both picker routing and order batching improve overall order picking performance [6]. The layout of the distribution centre has been considered as a factor affecting order picking efficiency [7]. The proposed research provides a new method for choosing between sequential zoning and simultaneous zoning for picker-to-parts system, in aim to help picking system designers in decision-making [8,9].

An order batching policy has a significant impact on the performance of the order picking system. In [10] a newly developed order batching approach is proposed, based on a group genetic algorithm in aim to balance the workload of each picking zone and minimize the number of batches in a "pick and pass". The results of simulation on the model formed in the FlexSim software package have shown that the proposed heuristic policy outperforms existing order batching policies in a "pick and pass" order picking system.

The pickers' activities can be described as a Markov's chain. On this basis analytic "pick and pass" models for zone order picking are developed, for the purpose of assessing the expected trajectories of the pickers along the picking line [11]. Based on the developed analytic models, studies have defined the basic principles and rules for determining the allocation of items within an individual order picking case, in case of both the equally and the differently sized zones.

Due to the above-mentioned issues, the need arose for the introduction of so-called dynamic zones into the order picking systems. Dynamic zones represent flexible work zones of the pickers, which, by adapting to the current structures of the orders, allow for a change in the zone boundaries over time. In this sense, a type of zone order picking was developed bearing the name bucket brigades method, under which the pickers mimic the cooperative behaviour of ants in the process of transferring food. With this type of zone order picking, execution of orders is achieved in the following manner: when the last picker in a sequence completes the extraction of items for a particular order, he returns to the previous picker from whom he takes the tote, and carries on with his work. The penultimate picker then goes back to his predecessor, from whom he takes the tote and resumes with his work. This procedure is constantly repeated, and in this manner is the order picking performed. If a difference in picking speed occurs between individual pickers, the slowest picker has to be repositioned at the beginning, and the remaining pickers accordingly positioned with the fastest picker being positioned at the end. The main advantage of the bucket brigade system is the enabling of a 
work balance among the pickers, however, time losses may occur due to certain zones becoming blocked [12]. Major changes in order structures and different picking speeds among the pickers represent the most difficult obstacle for balancing the work of the pickers over a longer period of time [13].

In order to reduce time losses in zone order picking systems, the method of zoned bucket brigades was developed, as a combination of classical zone order picking and order picking with bucket brigades [14]. The picking line is divided into $m$ zones, at whose boundaries $m-1$ temporary storages are placed. The principle of operation is as follows: after the execution of an order, a picker leaves the tote in the temporary storage at the end of his zone and returns either to the previous temporary storage, where he takes the tote and begins to execute the next order. If the previous temporary storage is empty, he goes to the previous picker from whom he takes a tote and continues with the order execution.

\section{METHODOLOGY}

The performance of an order picking system is determined by several factors, as described briefly in the previous section. The question is whether the sequence of order execution can affect the performance of order picking systems?

When routing delays result from warehouse configurations, $[15,16]$ show how to manage order batching and order release sequences to reduce congestion. The impact of different storage policies, picking strategies and number of pickers on congestion and picking efficiency in specific conditions is analysed in the paper [17].

In the order picking process, the picker moves along the picking line, stopping at the picking locations and picking up items for the order that he is executing (marked by black circles in Fig. 1), and passing the locations where there are no items to be extracted - cavities. If the number of different items to be extracted is small compared to the total number of items, a large number of cavities occur. Also, areas are occurring in which there is a large number of zones in succession, containing no items to be extracted. According to Fig. 1, these are the positions 8-10,12-13,15-16, 18-21 and 28-30. These areas are called bound cavities.

The structure of order picking time consists of the time necessary to extract an item and the time necessary for the picker to move between the positions. If the work of two pickers in a "pick and pass" zone order picking system is observed, it is obvious that the time intervals related to items extraction cannot be avoided, and that they can only be redistributed among the pickers. In terms of travelling time, if it is technically possible to send the tote by conveyor from the first picker to the next, it would be optimal to perform the zone change at the location of the longest travel by the picker without the extraction of any items, i.e. at the largest bound cavity (locations 18 to 21, Fig. 1). In this way, the activities, and thus the picking times, would avoid movements of the pickers in both directions, along the section where there are no items to be extracted.

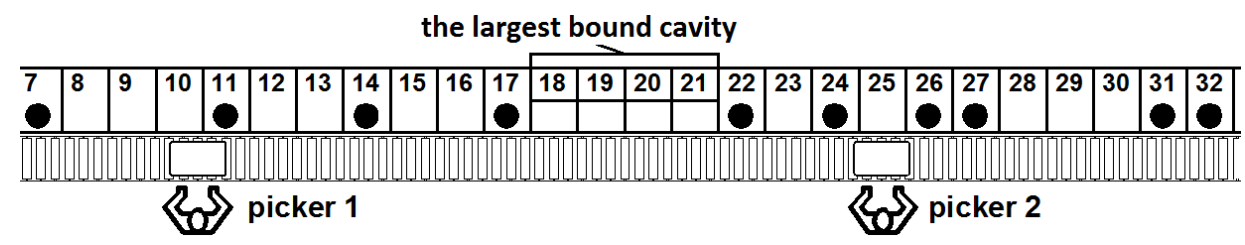

Figure 1: Picking line with two pickers.

This is the reason why the bound cavities method was developed, which aims to have the change of pickers or zones, performed precisely at the position where the largest bound cavities occur. In order to implement the method, a pick to light order picking system is required with two roller conveyors. The second (driven) conveyor is located under the picking 
locations in the area next to the first one, and the pickers push the totes during picking along it, Fig. 2. Empty totes arrive along the roller conveyor 2 and stop under the picking location where the first zone begins for the current order. The picker 1 transfers and pushes the tote along the nondriven roller conveyor 1 . After extracting the required number of items from a particular picking location, each picker presses a button to confirm that he has taken a sufficient number of items. At that moment, a light turns on at the next picking location from which it is necessary to extract items. A picker approaches the light, observes how many items need to be taken and begins to extract them. This procedure is repeated until the moment when the control system informs the picker to transfer the tote onto the roller conveyor 2, and after that he moves towards the beginning of the picking line and begins to execute the next order. The tote is transported by the roller conveyor 2 to the picking location where the zone of the next picker begins.

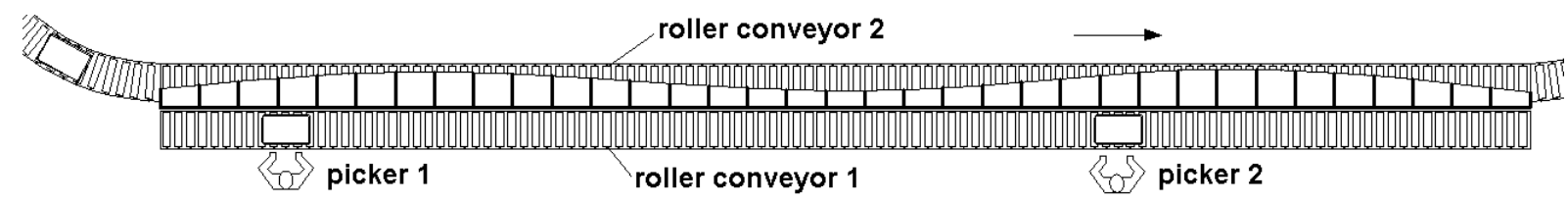

Figure 2: Order picking system layout.

An analysis of the picking process beginning in a system with two pickers leads to the conclusion that the order minimally engaging the picker 1 should be dealt with as the first one, in aim to minimize the waiting time of the picker 2. But, an analysis of the picking process ending indicates that the order minimally engaging the picker 2 should be dealt with as the last one, in aim to minimize the idle time of the picker 1 . To avoid/minimize the waiting time of the picker 1 after the first order, he should have much more work to do in the second order than the picker 2. Similar situation is encountered at the end of the picking process. The method defines the sequence of order execution during order picking which resembles the letter $X$, hence the name of the procedure [18].

The developed method can be applied to zone order picking systems with any number of pickers. Fig. 3 shows the sequence of order execution for a system with four pickers, where the lines represent the loads on the pickers.

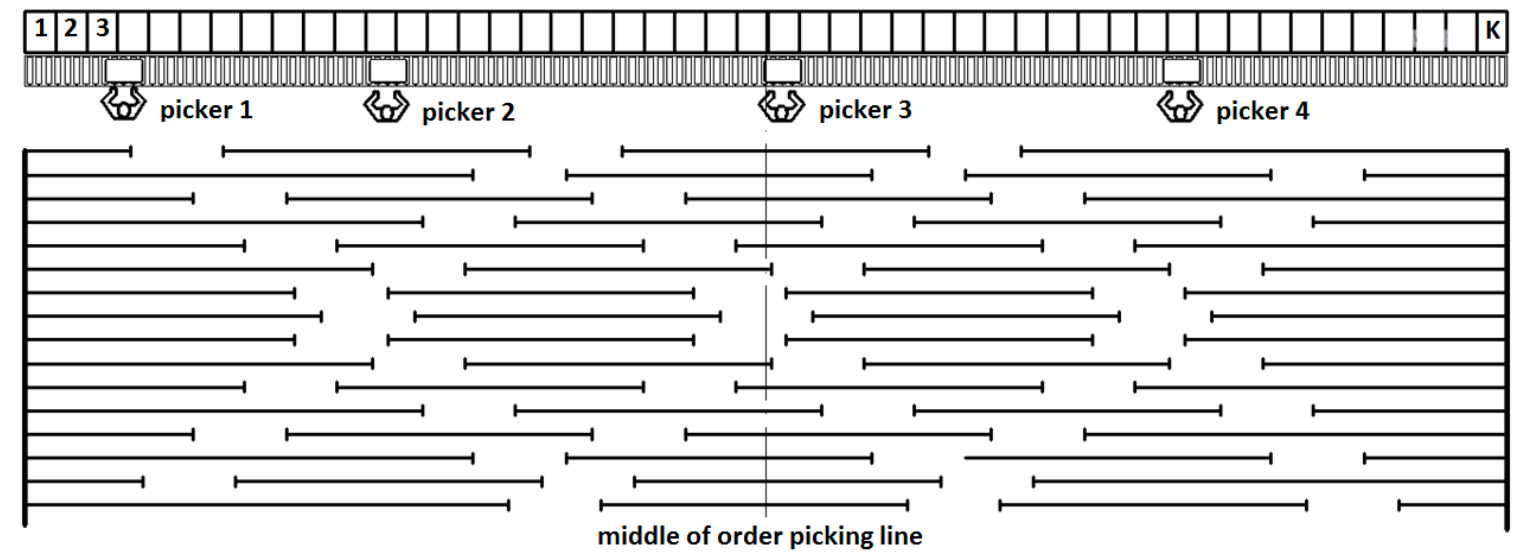

Figure 3: The sequence of order execution in systems with four pickers - triple $\mathrm{X}$ procedure of the bound cavities method.

The developed bound cavities method can be applied in a distribution centre in which the order picking is executed by spending a certain period of time (e.g. 1 hour) to collect the orders, analyse them and define the sequence before they are forwarded to be executed. While that particular group of orders is being executed, new groups are collected, and the process is then repeated. This is particularly interesting in a situation when a relatively large number of 
orders is coming in with a small number of different items to be extracted per each order, as is the case with e-shopping.

\subsection{Calculation of picking time using the bound cavities method}

The analysis, calculations of the total picking time, and potential savings, using the bound cavities method, are performed for a system with two and three pickers. By analogy, on the basis of this, appropriate expressions for the arbitrary number of pickers can be formed.

In the structure of activities and their durations in zone order picking with two pickers, it is possible to differentiate working time of the first and second picker on the $I^{\text {th }}$ order $\left(t_{1 R}^{I}, t_{2 R}^{I}\right)$, the return time of the first and second picker on the $I^{\text {th }}$ order $\left(t_{1 P}^{I}, t_{2 P}^{I}\right)$ and the time necessary for the tote to arrive by the roller conveyor from the end of the first zone to the beginning of the second zone on the $I^{\text {th }}$ order $\left(t_{K}^{I}\right)$ [18].

The total order picking time can be divided into:

- the setup time (the time for preparing the tour through the distribution centre),

- the travel time (the time needed to travel to, from, and between the pick locations),

- the searching time (the time needed for the identification of the items that have to be retrieved at the article locations), and

- the picking time (the time actually needed for retrieving the items from the respective article locations) [1].

Among these components, the travel time consumes the major proportion of the total order picking time. It also represents the only variable part while the remaining components of the total order picking time (setup time, search time, pick time) can be considered as constants [19].

Taking the above into account, the structure of the working picking time consists of:

- the time required for observing the light on a shelf turned on $\left(T_{S V}\right)$,

- the travel time of the picker towards the light, i.e. the next picking location from which an item has to be extracted,

- the time necessary to observe and read the number on the display next to the light $\left(T_{U B}\right)$,

- the time necessary to extract one item $\left(T_{U A}\right)$, and

- the time necessary to press the button next to the light to confirm that the required number of items has been extracted $\left(T_{P D}\right)$.

If a picking zone contains $K$ items with an equal number of picking positions, and if the largest bound cavity in the $I^{\text {th }}$ order, of size $m^{I}$, occurs at position $j_{1}^{I}$, then the working time and the return time can be calculated according to:

$$
\begin{gathered}
t_{1 R}^{I}=r_{1}^{I} \cdot\left(T_{S V}+T_{U B}+T_{P D}\right)+a_{1}^{I} \cdot T_{U A}+\left(\left(j_{1}^{I}-p_{1}^{I}\right) \cdot b_{K M}\right) / v_{K R} \\
t_{1 P}^{I}=\left(\left(j_{1}^{I}-p_{1}^{I+1}\right) \cdot b_{K M}\right) / v_{K R} \\
t_{2 R}^{I}=r_{2}^{I} \cdot\left(T_{S V}+T_{U B}+T_{P D}\right)+a_{2}^{I} \cdot T_{U A}+\left(\left(j_{2}^{I}-p_{2}^{I}\right) \cdot b_{K M}\right) / v_{K R} \\
t_{2 P}^{I}=\left(\left(j_{2}^{I-1}-p_{2}^{I}\right) \cdot b_{K M}\right) / v_{K R} \\
t_{K}^{I}=\left(m^{I} \cdot b_{K M}\right) / v_{V T}
\end{gathered}
$$

where:

- $p_{1}^{I}, p_{2}^{I}, j_{1}^{I}, j_{2}^{I}$ are numerical addresses of the beginning and the ending points of the first and second zone (respectively) in the $I^{\text {th }}$ order,

- $r_{1}^{I}, r_{2}^{I}$ are the numbers of different items that the first and second picker have to extract in the $I^{\text {th }}$ order,

- $a_{1}^{I}, a_{2}^{I}$ are the total numbers of items where the picker 1 and the picker 2 have to extract in the $I^{\text {th }}$ order, 
- $v_{K R}$ is the travel speed of the picker,

- $v_{V T}$ is the speed of roller conveyor,

- $b_{K M}$ is the width of one picking place,

- $m^{I}$ is the number of picking places between the zones in the $I^{\text {th }}$ order.

The total picking time required for executing the group of $N$ orders in a system with two pickers can be calculated as:

$$
T^{2 P}=\sum_{I=1}^{N}\left(t_{1 R}^{I}+t_{1 P}^{I}\right)+\sum_{I=1}^{N} t_{12 C}^{I}+t_{21 K}^{N}+t_{2 R}^{N}-t_{1 P}^{N}
$$

where:

- $\sum_{I=1}^{N} t_{12 C}^{I}$ is the total waiting and blocked time of picker 1 in all of the orders,

- $t_{21 K}^{N}$ is the delay time of picker 2 in relation to picker 1 , after picker 1 completed his part of work in the last order,

- $t_{2 R}^{N}$ is the working time of picker 2 in the last order,

- $t_{1 P}^{N}$ is the return time of picker 1 in the last order.

In order to calculate picking time, the diagram shown in Fig. 4 is used. The diagram is filled in with the working time and the return time of the pickers, as well as the travel time of the tote along the roller conveyor, by entering the locations of the picking positions on the $\mathrm{x}$ axis, and time on the y-axis.

In an ideal case, after the picker 1 executed the second order (point 5), the tote arrives at point 6 (where the second zone begins) at the same moment as the picker 2 . This would mean that the loads on the pickers in adjacent orders are equal, and that there are no time losses in the work of either picker. As this is most often not the case, the picker 2 may arrive early and has to wait, or he may be delayed as shown in Fig. 4. The distance between points 6 and 7 represents the delay of the picker 2 .

In [15] strategies to control picker blocking are presented, that challenge the traditional assumptions regarding the trade-offs between wide-aisle and narrow-aisle order picking systems. The obtained results indicate that the proposed approach achieves a 5-15\% shortening of the total retrieval time primarily by shortening the picker blocking.

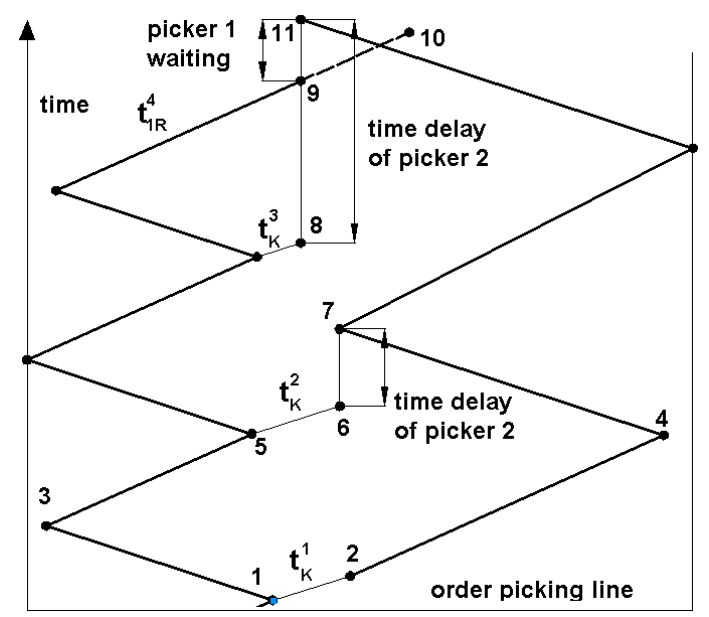

Figure 4: The basic order picking layout for a system with two pickers.

A longer delay of the picker 2 causes a time loss and forces the picker 1 to wait. Accordingly, a situation can emerge, as shown in the Fig.4, when the picker 1 executed the third order, left the tote, which has via roller conveyor reached the beginning of the second zone (point 8), after the picker 1 headed back and continued with the execution of the fourth order. During that time, the picker 2 was executing the second order, after which he headed back to the tote of the third order. If the first zone ending point location of the fourth order 
(point 10) is behind the second zone beginning point location of the third order (point 11), and the picker 2 is delayed, then the picker 1 is unable to execute his part of the extraction for order 4, and becomes blocked at point 9 . The blocking is in the temporal sense equal to the distance between points 9 and 11. In order to be able to include the given occurrence into the calculation of the total picking time, it is necessary to do the following:

- Calculate the working and return times of both pickers, as well as the travel time of the tote along the roller conveyor for all of the orders.

- Calculate the individual values in the expression $\left(t_{1 R}^{I+1}+t_{K}^{I+1}-t_{2 P}^{I+1}-t_{K}^{I}-t_{2 R}^{I}+t_{1 P}^{I}\right)$ for all of the adjacent orders, and thus determine the delay of the picker 1 (if the expression is greater than 0) or the delay of the picker 2 (if the expression is less than 0) in the observed order, where the delay of the picker 1 is not included into the total picking time, while the delay of the picker 2 must be cumulatively calculated:

$$
\begin{gathered}
t_{12 \mathrm{~K}}^{I+1}=t_{1 R}^{I+1}+t_{K}^{I+1}-t_{2 P}^{I+1}-t_{K}^{I}-t_{2 R}^{I}+t_{1 P}^{I} \\
t_{21 \mathrm{~K}}^{I+1}=t_{21 \mathrm{~K}}^{I}+\left(t_{2 P}^{I+1}+t_{K}^{I}+t_{2 R}^{I}-t_{1 P}^{I}-t_{1 R}^{I+1}-t_{K}^{I+1}\right)
\end{gathered}
$$

- Calculate working and return time of the picker 1, calculate the cumulative delay of the picker 2, at which a delay of the picker 1 reduces the delay of the picker 2. After that, check the waiting time of the picker 1 in a situation when the second zone beginning point location of the previous order is in front of the first zone ending point location of the current order. Then add the waiting times of the picker 1 in individual time intervals to the total order picking time, which is based on Fig. 4, and calculated as:

$$
t_{12 C}^{I+1}=t_{K}^{I}+t_{21 \kappa}^{I+1}-\left(t_{1 P}^{I}+t_{1 R}^{I+1} \cdot \frac{p_{2}^{I}-p_{1}^{I+1}}{j_{1}^{I+1}-p_{1}^{I+1}}\right)
$$

The total picking time required for executing a group of $N$ orders in a system with three pickers, can be calculated as:

where:

$$
T^{3 P}=\sum_{I=1}^{N}\left(t_{1 R}^{I}+t_{1 P}^{I}\right)+\sum_{I=1}^{N} t_{12 C}^{I}+t_{21 \mathrm{~K}}^{N}+t_{2 R}^{N}-t_{1 P}^{N}+t_{32 \mathrm{~K}}^{N}+t_{3 R}^{N}
$$

- $\sum_{I=1}^{N} t_{12 C}^{I}$ is the total waiting and blocked time of picker 1 in all of the orders,

- $t_{21 \mathrm{~K}}^{N}$ is the delay time of picker 2 in relation to picker 1 , after picker 1 completed his part of the work in the last order,

- $t_{32 \mathrm{~K}}^{N}$ is the delay time of picker 3 in relation to picker 2, after picker 2 completed his part of the work in the last order.

In order to calculate the total picking time, the diagram shown in Fig. 5 will be used.

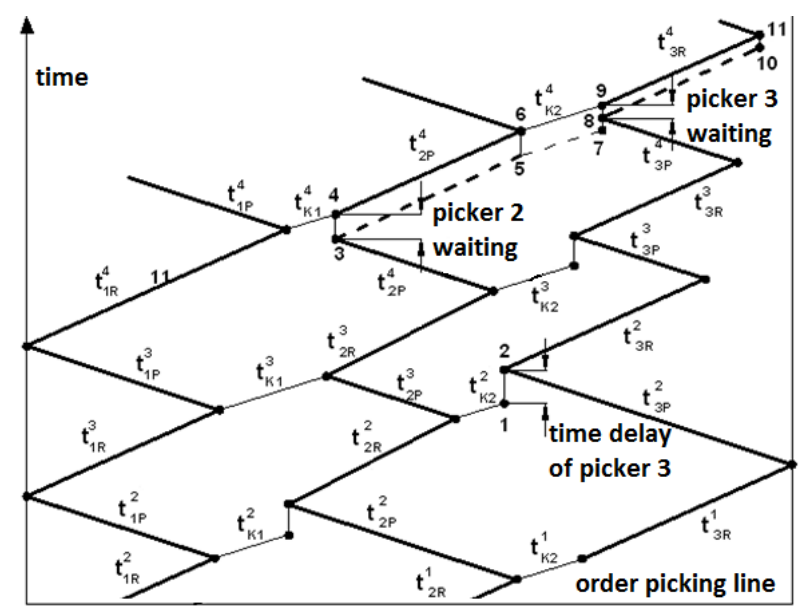

Figure 5: The basic order picking layout for a system with three pickers. 
In this case, the analysis of the work for the system with two pickers, it is necessary to add the picker 3, as well as the influence of the picker 3 on the work of the picker 2. Delays may occur (from point 1 to 2 ) and waiting for the picker 3 (from points 8 to 9). The influence of waiting of the picker 2 in relation to the picker 1 , on the work of the picker 3 must be considered. In the situation shown in Fig. 5, due to the waiting of the picker 2 (from point 3 to 4) the picker 3 has to wait from point 8 to 9 . If the picker 2 had not waited, the delay from point 7 to 8 would have occurred. In order to be able to include the given occurrence into the calculation of the total picking time, it is necessary to do the following:

- After defining the zone boundaries in all of the orders, calculate the working time and the return time of all three pickers, as well as the travelling time of the tote along the roller conveyor, at both points of zone change, for all of the orders.

- Calculate the individual values in the expression $\left(t_{1 R}^{I+1}+t_{K 1}^{I+1}+t_{1 P}^{I}-t_{2 P}^{I+1}-t_{K 1}^{I}-t_{2 R}^{I}\right)$ for all of the adjacent orders, and thus determine the delay of the picker 1 (if the expression is greater than 0) or the delay of the picker 2 (if the expression is less than 0) in the observed order. In this case, it is necessary to observe the previous conditions, or if the previous work may have caused a delay of the picker 2 . If yes, then it must be calculated whether the waiting or the delay of the picker 2 occurs after the current order. If waiting occurs, this does not affect the work of the picker 1 , but affects the work of the picker 3 . If delay occurs, it must be verified that this can subsequently lead to blocking zone 1 . If the expression is less than 0 , there is a delay of the picker 2 , which does not affect the work of the picker 3. In doing so, the delay of the picker 1 is not calculated in the total picking time, while the delay of the picker 2 must be cumulatively calculated. In both cases, the possible waiting of the picker 2 must also be accounted for the picking of the picker 3 during the execution of the previous order, according to the expressions:

$$
\begin{gathered}
t_{12 \mathrm{~K}}^{I+1}=t_{1 R}^{I+1}+t_{K 1}^{I+1}-t_{2 P}^{I+1}-t_{K 1}^{I}-t_{2 R}^{I}+t_{1 P}^{I}-t_{23 C}^{I-1} \\
t_{21 \mathrm{~K}}^{I+1}=t_{21 \mathrm{~K}}^{I}+\left(t_{2 P}^{I+1}+t_{K 1}^{I}+t_{2 R}^{I}-t_{1 P}^{I}-t_{1 R}^{I+1}-t_{K 1}^{I+1}\right)+t_{23 C}^{I-1}
\end{gathered}
$$

where $t_{23 C}^{I-1}$ is the waiting of the picker 2 in relation to the picker 3 during execution of the $(I-1)^{\text {th }}$ order.

Checking the possible waiting of the picker 1 must be carried out in a situation where the location of the beginning of the second zone of the previous order, is in front of the location of the end of the first zone of the current order. Waiting of the picker 1 at certain time intervals, must be added to the total picking time, and is calculated according to the Eq. (9). It is necessary in this case to calculate the waiting of the picker 2 as a result of the work of the picker 1, because this affects the relationship between the pickers 2 and 3 . The calculation has to be performed as follows:

$$
t_{21 C}^{I+1}=t_{1 R}^{I+1}+t_{K 1}^{I+1}-t_{2 P}^{I+1}-t_{K 1}^{I}-t_{2 R}^{I}+t_{1 P}^{I}
$$

Similar to the previous analysis, it is necessary to carry out an analysis of the work of pickers 2 and 3, i.e. first to calculate the individual values of the following parameters, according to Fig. 6:

$$
\begin{gathered}
t_{23 \mathrm{~K}}^{I+1}=t_{2 R}^{I+1}+t_{K 2}^{I+1}-t_{3 P}^{I+1}-t_{K 2}^{I}-t_{3 R}^{I}+t_{2 P}^{I}+t_{21 C}^{I+1} \\
t_{32 \mathrm{~K}}^{I+1}=t_{32 \mathrm{~K}}^{I}+\left(t_{3 P}^{I+1}+t_{K 2}^{I}+t_{3 R}^{I}-t_{2 P}^{I}-t_{2 R}^{I+1}-t_{K 2}^{I+1}\right)-t_{21 C}^{I+1} \\
t_{23 C}^{I+1}=t_{K 2}^{I}+t_{32 \mathrm{~K}}^{I+1}-\left(t_{2 P}^{I}+t_{2 R}^{I+1} \cdot \frac{p_{3}^{I}-p_{2}^{I+1}}{j_{2}^{I+1}-p_{2}^{I+1}}\right)
\end{gathered}
$$

where:

- $t_{23 \mathrm{~K}}^{I+1}$ is the delay of the picker 2 in relation to the picker 3 , at the moment when the picker 2 starts to work in the $(I+1)^{\text {th }}$ order,

- $t_{32 \mathrm{~K}}^{I+1}$ is the delay of the picker 3 in relation to the picker 2 , at the moment when the picker 3 starts to work in the $(I+1)^{\text {th }}$ order. 
Waiting of the picker 3 in relation to the picker 2 does not affect the relationship with other pickers, as well as with the total picking time.

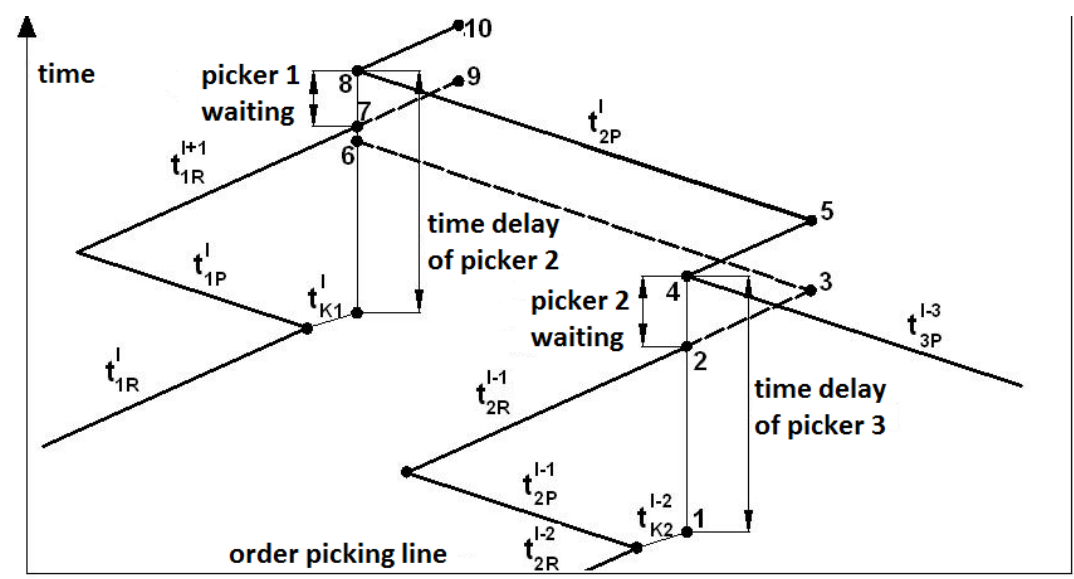

Figure 6: The influence of the picker 3 delays on the work of other pickers.

\subsection{Time savings using the bound cavities method}

Improving the performance of the order picking system by using the bound cavities method, can be presented through savings in the total picking time (potential time savings) and savings in the pickers' travelled paths. The potential time savings will be explained here.

Potential time savings in the system with two pickers and $N$ orders, using the bound cavities method, with the automatic movement of the tote by the roller conveyor from the end of the first zone to the beginning of the second zone, as well as to the beginning of the first zone, and from the end of the second zone to the end of the picking line, can be calculated according to the expression:

$$
\mathrm{T}_{T S}^{2 P}=\sum_{I=1}^{N} \frac{b_{K M}}{v_{K R}} \cdot\left(\left(p_{2}^{I}-\mathrm{j}_{1}^{I}\right)+\left(p_{1}^{I}-1\right)+\left(K-j_{2}^{I}\right)\right)
$$

where $K$ is the total number of picking places in the order picking line.

The total picking time in the zoned bucket brigades order picking system with two pickers will be used as a comparative picking time, in the case where there is no time loss described in [14], which is calculated according to:

$$
\mathrm{T}_{Z B B}^{2 P}=\sum_{I=1}^{N}\left(\frac{1}{2} \cdot\left(\left(r_{1}^{I}+r_{2}^{I}\right) \cdot\left(T_{S V}+T_{U B}+T_{P D}\right)+\left(a_{1}^{I}+a_{2}^{I}\right) \cdot T_{U A}+2 \cdot \frac{K \cdot b_{K M}}{v_{K R}}\right)\right)
$$

The time to execute group of $N$ orders in the system with two pickers, using the bound cavities method, can be calculated according to Eq. (6).

Potential time savings in the system with three pickers and $N$ orders, using the bound cavities method, with the automatic movement (by the roller conveyor) of the tote between the zones, as well as to the beginning of the first zone, and from the end of the third zone to the end of the picking line, can be calculated according to the expression:

$$
\mathrm{T}_{T S}^{3 P}=\sum_{I=1}^{N} \frac{2 \cdot b_{K M}}{3 \cdot v_{K R}} \cdot\left(\left(p_{2}^{I}-\mathrm{j}_{1}^{I}\right)+\left(p_{3}^{I}-\mathrm{j}_{2}^{I}\right)+\left(p_{1}^{I}-1\right)+\left(K-j_{2}^{I}\right)\right)
$$

As a comparative picking time, the picking time in the order picking system of zoned bucket brigades with three pickers will be used, which is calculated according to:

$$
\mathrm{T}_{Z B B}^{3 P}=\sum_{I=1}^{N}\left(\frac{1}{3}\left(\left(r_{1}^{I}+r_{2}^{I}+r_{3}^{I}\right) \cdot\left(T_{S V}+T_{U B}+T_{P D}\right)+\left(a_{1}^{I}+a_{2}^{I}+a_{3}^{I}\right) \cdot T_{U A}+\frac{2 \cdot K \cdot b_{K M}}{v_{K R}}\right)\right)
$$


The total picking time to execute group of $N$ orders in the system with three pickers, using the bound cavities method, can be calculated according to Eq. (10).

\section{SIMULATION RESULTS}

Different logistic processes can be simulated on formed models [20]. Many authors have worked on simulations of the order picking system. On the formed models, three groups of articles $\mathrm{A}, \mathrm{B}$ and $\mathrm{C}$ were considered, with the probability of finding in each order in groups of 50,30 and $20 \%$ in relation to the total number of items [21]. The number of articles on orders was 100, 500 and 1000, and 10 repetitions for each variant were carried out.

On the analysed models were applied the travel speed of the picker $0,6 \mathrm{~m} / \mathrm{s}$, and the average number of items per order was 30 [22]. The sizes of the zones, on the considered models were 96, 288 and 576 items [5]. Order structure consisted of 1, 5, 10, 20 and 30 items. On the analysed models the average travel speed of the picker of $0,5 \mathrm{~m} / \mathrm{s}$ was used, 5 repetitions for each case were performed, in which there were 250 orders with 100 different items [23]. Three performance systems were monitored: picked travel time, total picking time and total time to exclude items.

Distribution of articles on the considered models was according to class and random order, with orders from 5, 10, 15, 20, 25, 30 and 40 items [24]. The order structure was 80/20 and $60 / 20$. The travel speed of the picker was $0,75 \mathrm{~m} / \mathrm{s}$. In the analysis based on the principle of zoned bucket brigades, the number of items per order is determined to be the random variable between 6 and 12. There were 150 different items on the picker line, divided into 3 zones. The number of pieces of particular items was a random variable between 1 and 3 .

The mathematical model of the "pick and pass" zone order picking system was created in Microsoft Office Excel. Simulations were performed on the created models, and the total picking time necessary to execute a group of $N$ orders is calculated. The input data for the simulations were: a travel speed of the picker $0,5 \mathrm{~m} / \mathrm{s}$, a roller conveyor speed $1 \mathrm{~m} / \mathrm{s}$, a single item extraction time $2 \mathrm{~s}$, the time necessary to detect a light and press the button of a length $2 \mathrm{~s}$, and a width of a picking position $0,5 \mathrm{~m}$.

The models were formed for systems with two and three pickers, while variants with 50 and 100 orders in a group were considered. The number of items in the picking line was 80 and 150 . The average number of items that are extracted per order was $35 \%$ and $90 \%$ of the total number of items. In order to define the structure of the orders, sequences of random numbers with an exponential distribution were generated. An appropriate number of random numbers was generated for different variants, representing information on the location and number of items for extraction per individual order (values $0,1,2$ or 3). As an example, for the variant with 80 items and 50 orders, 4000 random numbers have been generated where random numbers from No. 1 to No. 80 were assigned to the first order, from No. 81 to No. 160 to the second order, ..., and finally from No. 3921 to No. 4000 to the last order (No. 50). In that case the generated random number in the position No. 97 represented the number of item pieces to be taken in the picking place No. 17 per second order, random number in the position No. 216 represented the number of item pieces to be taken in the picking place No. 56 per third order, etc.

The basic assumption of the model is that there is always a sufficient number of items at the picking locations, and that all of the items are extracted with the same probability. Simulated were order picking systems with zoned bucket brigades and dynamic zones execution sequence according to the bound cavities method. Ten repetitions were performed for each variant.

The results for an order picking system using the bound cavities method in the system with two and three pickers are given in Table I. The comparative values for the total picking time, in all of the variants, were the results for the system of zoned bucket brigades. 
Table I: Results for an order picking system with two and three pickers.

\begin{tabular}{|c|c|c|c|c|c|c|c|c|c|}
\hline $\begin{array}{l}\text { Variant of order } \\
\text { picking system }\end{array}$ & 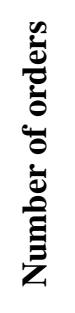 & 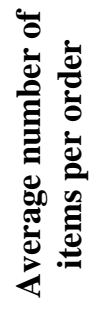 & 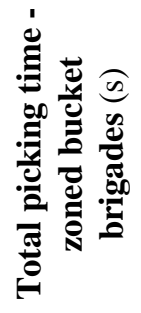 & 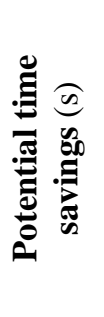 & 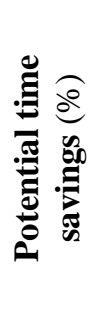 & 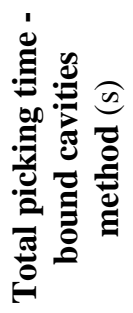 &  & 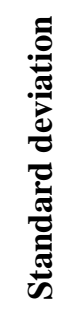 & 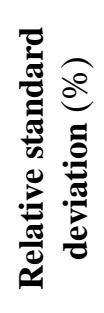 \\
\hline \multirow{2}{*}{ 2P 80 pp $35 \% *$} & 50 & 27,9 & 7612 & 438 & 5,75 & 7417 & 2,56 & 135 & 1,82 \\
\hline & 100 & 28,3 & 15166 & 869 & 5,73 & 14802 & 2,40 & 321 & 2,17 \\
\hline \multirow{2}{*}{ 2P 80 pp $90 \%$} & 50 & 72,6 & 12062 & 248 & 2,06 & 11920 & 1,18 & 251 & 2,11 \\
\hline & 100 & 72,2 & 24042 & 490 & 2,04 & 23775 & 1,11 & 414 & 1,74 \\
\hline \multirow{2}{*}{$2 \mathrm{P} 150$ pp $35 \%$} & 50 & 49,2 & 13834 & 516 & 3,73 & 13559 & 1,99 & 309 & 2,28 \\
\hline & 100 & 49,6 & 28058 & 1038 & 3,70 & 27516 & 1,93 & 539 & 1,96 \\
\hline \multirow{2}{*}{ 2P 150 pp $90 \%$} & 50 & 133,3 & 22291 & 321 & 1,44 & 22108 & 0,82 & 456 & 2,06 \\
\hline & 100 & 130,0 & 43862 & 636 & 1,45 & 43480 & 0,87 & 956 & 2,20 \\
\hline \multirow{2}{*}{ 3P 80 pp $35 \%$} & 50 & 28,8 & 5036 & 410 & 8,14 & 4902 & 2,67 & 76 & 1,55 \\
\hline & 100 & 28,5 & 10129 & 843 & 8,17 & 9852 & 2,74 & 171 & 1,74 \\
\hline \multirow{2}{*}{ 3Р 80 pp $90 \%$} & 50 & 71,1 & 8019 & 212 & 2,65 & 7916 & 1,28 & 108 & 1,36 \\
\hline & 100 & 72,2 & 15835 & 426 & 2,69 & 15639 & 1,24 & 342 & 2,19 \\
\hline \multirow{2}{*}{$3 \mathrm{P} 150$ pp $35 \%$} & 50 & 51,8 & 9571 & 447 & 4,67 & 9344 & 2,37 & 312 & 3,34 \\
\hline & 100 & 51,6 & 18556 & 861 & 4,64 & 18112 & 2,39 & 412 & 2,27 \\
\hline \multirow{2}{*}{ 3P 150 pp $90 \%$} & 50 & 129,9 & 14504 & 320 & 2,20 & 14324 & 1,24 & 312 & 2,18 \\
\hline & 100 & 129,7 & 29541 & 643 & 2,18 & 29166 & 1,27 & 743 & 2,55 \\
\hline
\end{tabular}

* Key: 2P 80 pp $35 \%$ - two pickers, 80 picking places, $35 \%$ - average number (\%) of items that are extracted per order of the total number of items

A graphical presentation of the potential and real total picking time savings using the bound cavities method, in a percentage ratio, according to the results for zoned bucket brigades, is given in Fig. 7. The graphs show the mean values for the 50 and 100 orders in the group.

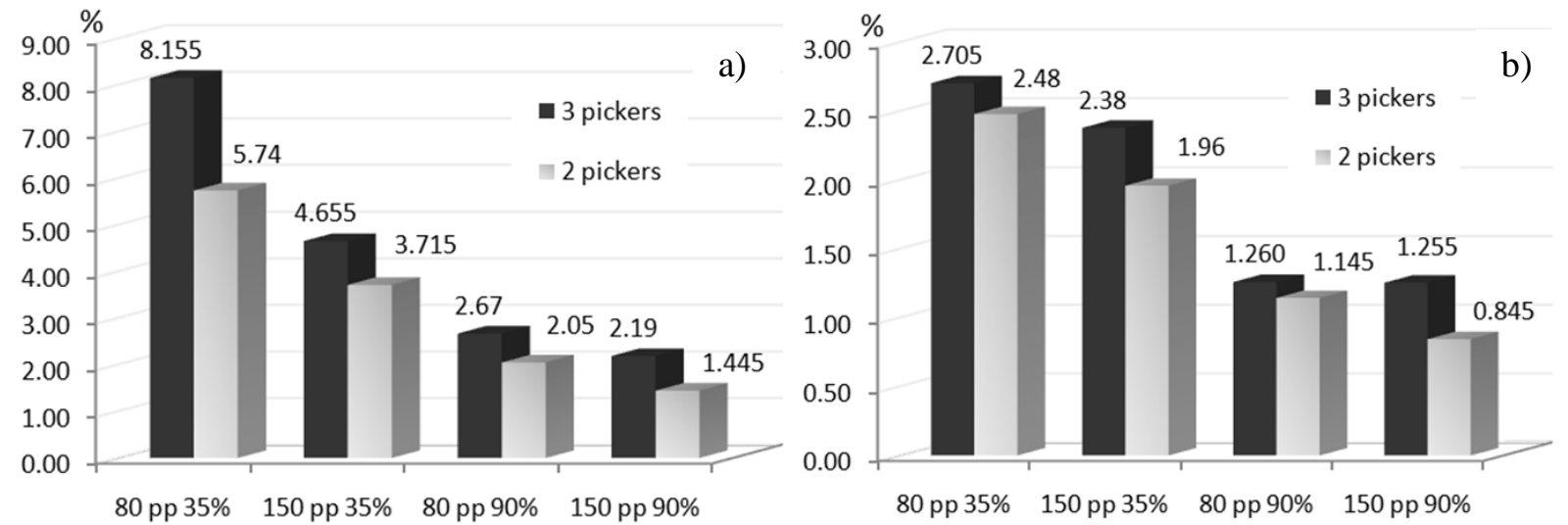

Figure 7: Potential (a) and real (b) total picking time savings using the bound cavities method.

\subsection{Discussion}

Based on the results of the simulations using the formed mathematical models, the following can be concluded:

- the adopted representative sample is 50 orders, as there are no significant differences in variants with 50 and 100 orders in the group, 
- by increasing the number of pickers, total picking time savings using the bound cavities method are also increasing,

- by increasing the average number of items per analysed orders, total picking time savings using the bound cavities method are reduced,

- by increasing the number of picking places, total picking time savings using the bound cavities method are reduced,

- if the size of a particular picking place is enlarged, total picking time savings using the bound cavities method are increasing,

- if the values of the time associated with pickers' activities $\left(T_{S V}, T_{U B}, T_{P D}, T_{U A}\right)$ are higher, total picking time savings using the bound cavities method are reduced,

- if the travel speed of the picker is higher, total picking time savings using the bound cavities method are reduced,

- increasing the number of pickers reduces the ratio of the actual and potential time savings, which means that it is more difficult to take advantage of the maximum possible savings.

\section{CONCLUSION}

Distribution centres play a critical role in satisfying customer demands in global supply chains. Despite large-scale automation, order picking activities in modern distribution centres are to a great extent performed manually. Order picking activities have become very complex, considering the occurrence of a large number of orders, with small quantities of different items. In such situations, satisfactory performance can be achieved only through the use of a "pick and pass" zone order picking system, with pick to light technology.

The main task of this paper was to investigate whether the sequence of order execution in a "pick and pass" zone order picking system can have an effect on the performance of the order picking system. For that purpose, the bound cavities method was developed in aim to define the sequence of order execution, in which the boundaries of the zones are placed at the locations of the largest bound cavity within the orders.

The results of the simulations on the created models showed that the use of the bound cavities method increased the performance of an order picking system, i.e. the total picking time was shortened. The use of the bound cavities method improves the performance of a "pick and pass" zone order picking system. In a real system, the considered method could be applied by monitoring the order picking system during its operation and adapting the sequence of execution to the current state (on-line).

\section{REFERENCES}

[1] Tompkins, J. A.; White, J. A.; Bozer, Y. A.; Tanchoco, J. M. A. (2010). Facilities Planning, $4^{\text {th }}$ edition, John Wiley \& Sons, Hoboken

[2] Lerher, T.; Borovinsek, M.; Ficko, M.; Palcic, I. (2017). Parametric study of throughput performance in SBS/RS based on simulation, International Journal of Simulation Modelling, Vol. 16, No. 1, 96-107, doi:10.2507/IJSIMM16(1)8.372

[3] Dujmešić, N.; Bajor, I.; Rožić, T. (2018). Warehouse processes improvement by pick by voice technology, Technical Gazette, Vol. 25, No. 4, 1227-1233, doi:10.17559/TV-20160829152732

[4] Jane, C. C. (2000). Storage location assignment in a distribution center, International Journal of Physical Distribution \& Logistics Management, Vol. 30, No. 1, 55-71, doi:10.1108/ 09600030010307984

[5] Petersen, C. G. (2002). Considerations in order picking zone configuration, International Journal of Operations \& Production Management, Vol. 22, No. 7, 793-805, doi:10.1108/ $\underline{01443570210433553}$ 
[6] De Koster, R.; Le-Duc, T.; Roodbergen, K. J. (2007). Design and control of warehouse order picking: a literature review, European Journal of Operational Research, Vol. 182, No. 2, 481501, doi:10.1016/j.ejor.2006.07.009

[7] Pohl, L. M.; Meller, R. D.; Gue, K. R. (2011). Turnover-based storage in non-traditional unitload warehouse designs, IIE Transactions, Vol. 43, No. 10, 703-720, doi: $\underline{10.1080 /}$ 0740817X.2010.549098

[8] Shen, C.; Wu, Y.; Zhou, C. (2011). Selecting between sequential zoning and simultaneous zoning for picker-to-parts order picking system based on order cluster and genetic algorithm, Chinese Journal of Mechanical Engineering, Vol. 24, No. 5, 820-828, doi:10.3901/cjme.2011.05.820

[9] Đurđević, D. B.; Miljuš, M. D. (2013). The procedure proposal for order pick area design, Technical Gazette, Vol. 20, No. 1, 85-91

[10] Pan, J. C.-H.; Shih, P.-H.; Wu, M.-H. (2015). Order batching in a pick-and-pass warehousing system with group genetic algorithm, Omega, Vol. 57, Part B, 238-248, doi:10.1016/ j.omega.2015.05.004

[11] Pan, J. C.-H.; Wu, M.-H. (2009). A study of storage assignment problem for an order picking line in a pick-and-pass warehousing system, Computers \& Industrial Engineering, Vol. 57, No. 1, 261-268, doi:10.1016/j.cie.2008.11.026

[12] Anderson, C.; Boomsma, J.; Bartholdi III, J. (2002). Task partitioning in insect societies: bucket brigades, Insectes Sociaux, Vol. 49, No. 2, 171-180, doi:10.1007/s00040-002-8298-7

[13] Bartholdi III, J. J.; Eisenstein, D. D. (1996). A production line that balances itself, Operations Research, Vol. 44, No. 1, 21-34, doi:10.1287/opre.44.1.21

[14] Koo, P.-H. (2009). The use of bucket brigades in zone order picking systems, OR Spectrum, Vol. 31, No. 4, Paper 759, doi:10.1007/s00291-008-0131-x

[15] Hong, S.; Johnson, A. L.; Peters, B. A. (2012). Batch picking in narrow-aisle order picking systems with consideration for picker blocking, European Journal of Operational Research, Vol. 221, No. 3, 557-570, doi:10.1016/j.ejor.2012.03.045

[16] Matthews, J.; Visagie, S. (2013). Order sequencing on a unidirectional cyclical picking line, European Journal of Operational Research, Vol. 231, No. 1, 79-87, doi:10.1016/ j.ejor.2013.05.011

[17] Klodawski, M.; Jachimowski, R.; Jasyna-Golda, I.; Izdebski, M. (2018). Simulation analysis of order picking efficiency with congestion situations, International Journal of Simulation Modelling, Vol. 17, No. 3, 431-443, doi:10.2507/IJSIMM17(3)438

[18] Živanić, D.; Vujić, G.; Kosec, B.; Stoić, A. (2014). Material flow enhancement in production assembly lines under application of zoned order picking systems, Metalurgija-Metallurgy, Vol. 53, No. 4, 681-684

[19] Henn, S.; Koch, S.; Doerner, K. F.; Strauss, C.; Wäscher, G. (2010). Metaheuristics for the order batching problem in manual order picking systems, Business Research, Vol. 3, No. 1, 82-105, doi:10.1007/BF03342717

[20] Kása, R.; Gubán, M.; Gubán, Á. (2016). Logistical processes of service system with special regard to their amelioration - a simulation model framework, Gyenge, B.; Kozma, T. (Eds.), Challenges in Process Management: Decision points, network systems and strategies in practice, Szent István University, Gyöngyös, 31-51

[21] Rim, S.-C.; Park, I.-S. (2008). Order picking plan to maximize the order fill rate, Computers \& Industrial Engineering, Vol. 55, No. 3, 557-566, doi:10.1016/j.cie.2008.01.012

[22] Roodbergen, K. J.; De Koster, R. (2001). Routing order pickers in a warehouse with a middle aisle, European Journal of Operational Research, Vol. 133, No. 1, 32-43, doi:10.1016/S03772217(00)00177-6

[23] Ho, Y.-C.; Chien, S.-P. (2006). A comparison of two zone-visitation sequencing strategies in a distribution centre, Computers \& Industrial Engineering, Vol. 50, No. 4, 426-439, doi:10.1016/j.cie.2005.11.002

[24] Petersen, C. G.; Aase, G. (2004). A comparison of picking, storage, and routing policies in manual order picking, International Journal of Production Economics, Vol. 92, No. 1, 11-19, doi:10.1016/j.ijpe.2003.09.006 